Review

\title{
Environmental Impact of Flame Retardants (Persistence and Biodegradability)
}

\section{Osnat Segev $^{1}$, Ariel Kushmaro ${ }^{2, *}$ and Asher Brenner ${ }^{1}$}

1 Unit of Environmental Engineering, Faculty of Engineering Sciences, Ben-Gurion University of the Negev, P.O.Box 653, Be’er-Sheva, 84105, Israel; E-Mails: segevos@bgu.ac.il (O. S.); brenner@bgu.ac.il (A. B.)

2 Department of Biotechnology Engineering, Faculty of Engineering Sciences, Ben-Gurion University of the Negev, P.O.Box 653, Be'er-Sheva, 84105, Israel

* Author to whom correspondence should be addressed; Email: arielkus@bgu.ac.il; Tel.: 972-86479024; Fax: 972-8-6472983

Received: 22 January 2009/Accepted: 3 February 2009/ Published: 5 February 2009

\begin{abstract}
Flame-retardants (FR) are a group of anthropogenic environmental contaminants used at relatively high concentrations in many applications. Currently, the largest market group of FRs is the brominated flame retardants (BFRs). Many of the BFRs are considered toxic, persistent and bioaccumulative. Bioremediation of contaminated water, soil and sediments is a possible solution for the problem. However, the main problem with this approach is the lack of knowledge concerning appropriate microorganisms, biochemical pathways and operational conditions facilitating degradation of these chemicals at an acceptable rate. This paper reviews and discusses current knowledge and recent developments related to the environmental fate and impact of FRs in natural systems and in engineered treatment processes.
\end{abstract}

Keywords: Biodegradation; Bioremediation; Brominated flame retardants; Dehalogenation; Flame retardants; Persistence. 


\section{Introduction}

Flame retardants (FR) comprise a diverse group of chemicals which are widely used at relatively high concentrations in many applications, including the manufacture of electronic equipment, textiles, plastic polymers and in the car industry [1]. The annual consumption of flame retardants is currently over 1.5 million tonnes [2]. The use of FRs is primarily to protect materials against ignition and to prevent fire-related damage. Room combustion tests comparing FR plastics with non-FR plastics conducted by the National Bureau of Standards (The National Institute of Standards and Technology) have shown that FR materials allow longer escape time, less heat release, less smoke and release of a lower concentration of toxic gases. These effects are due to a decrease in the amount of burning materials [3].

More than 175 different types of FRs exist, commonly divided into four major groups: inorganic FRs, organophosphorus FRs, nitrogen-containing FRs and halogenated organic FRs (Figure 1) [1,4]. Inorganic FRs comprise metal hydroxides (e.g. aluminium hydroxide and magnesium hydroxide), ammonium polyphosphate, boron salts, inorganic antimony, tin, zinc and molybdenum compounds, as well as elemental red phosphorous. Inorganic FRs are added as fillers into the polymers and are considered immobile, in contrast to the organic additive FRs. Organophosphorous FRs are primarily phosphate esters that may also contain bromine or chlorine. Organophosphorous FRs are widely used both in polymers and textile cellulose fibers. Nitrogen-containing FRs inhibit the formation of flammable gases and are primarily used in polymers containing nitrogen, such as polyurethane and polyamide. The most important nitrogen-based FRs are melamine and melamine derivatives. Halogenated organic FRs are usually based on chlorine and bromine. Brominated flame retardants (BFR) are more numerous than chlorinated FRs due to their efficiency and because at high temperatures, the decomposition products of brominated compounds are less volatile than are those derived from chlorinated compounds, since bromine is heavier than chlorine [5]. Based on their structure, halogenated FRs can be divided into three classes, namely aliphatic, cycloaliphatic and aromatic, as exemplified by dibromoneopentyl glycol (DBNPG), hexabromocyclododecane (HBCD) and tetrabromobisphenol A (TBBPA), respectively (Figure 1D-F) [4,6].

Although FRs chemically differ from one another, shared general mechanisms of action distinguish between various classes of FRs. Generally, FRs are divided as being gas-phase active or condensedphase active, with the condensed-phase mechanisms of action being more common than the gas-phase ones. Further division is based upon the mechanism of action, namely chemical or physical. Some FRs (e.g. metal hydroxide like aluminum hydroxide) rely almost exclusively on a physical mechanism of action, whereas chemical mechanisms are always accompanied by one or more physical mechanisms. A combination of several mechanisms can be synergistic. The chemical mechanism of action of gasphase-active FRs involves a scavenging of free radicals responsible for the branching of the radical chain reaction in the flame. The physical mechanism of action in the gas phase is to generate large amounts of non-combustible gases, which dilute flammable gases and decrease temperatures by absorbing heat. The most frequent condensed-phase mode of action is charring, which can be implemented by chemical interaction of the FR and the plastic polymer or by physical retention of the plastic polymer in the condensed phase [3]. 
The mode of incorporation into polymeric material divides the FRs into two additional classes, namely reactive or additive. Reactive FRs are chemically bonded into plastics, e.g. HET acid (chlorendic acid), TBBPA, DBNPG or different organophosphorus compounds. Additive FRs are numerous and more frequently used. They are blended with the polymers and are thus more likely to leach out of products, e.g. HBCD, aluminium trihydrate, magnesium hydroxide and phosphate esters $[5,6]$.

FRs can find their way into the environment as wastewaters of industrial facilities that produce FRs and manufacturing facilities that incorporate such compounds into products, through volatilization and leaching from products during manufacturing or usage, upon breakdown of foam products or by disposal of products (e.g. electronic equipments), through leaching from landfills, combustion and recycling of waste products or adsorption onto dust particles [7,8]. In addition, additive FRs are believed to be more easily released into the environment than are reactive FRs [1]. Once a FR arrives into the environment, it can be attached to a particle for transport in water or delivery to the sediment or end up on an airborne dust particle and travel distances far from the production and/or emission site. Thus, traces of FRs (halogenated and organophosphorous-containing) are found in terrestrial, freshwater and marine ecosystems (i.e. in air, water, soil and sediments) at various locations, far from where they are produced and/or used [4,7,9-15].

Currently, because of their high performance efficiency and low cost, the largest market group of FRs is the BFRs [4]. Hence, we will further focus on the environmental impact of this group of compounds.

\section{Brominated flame retardants}

BFRs are used in a wide variety of indoor and outdoor products, including televisions, computers, microwave ovens, copy machines, lamp shades, textiles and furniture, where they constitute 5-30\% of the product $[4,6,8]$. The global market demand for BFRs continues to grow and it is estimated that more than 200,000 tonnes of BFRs are produced globally each year. Among the many BFRs used world-wide, the main commercial BFRs are TBBPA, HBCD and polybromodiphenyl ethers (PBDE) [4]. All BFRs primarily act through chemical interference with the radical chain mechanism that takes place during the gas phase of combustion [16,17].

In general, halogen substituent characteristics, such as an electron-withdrawing ability and physical size and shape, impact the chemical reactivity of the compound. The physical size and shape of the halogen substituent may delay uptake into cells and enzymatic attack during biodegradation. The halogen moiety of an organic compound increases lipid solubility and reduces water solubility. In addition, the halogen substituent and its potential organohalide metabolites may increase the inherent toxicity of a compound. Thus, due to bromide(s) substituent(s), many BFRs are toxic (acute and chronic), persistent and bioaccumulate in the environment [18]. Since the early 1970s, increasing evidence as to the presence of different BFRs in the environment at various locations, far from where they are produced and/or used (the latest publications have even shown levels of BFRs in the Arctic) has amassed, eliciting enormous environmental concern. BFRs at different concentrations have been measured in indoor and outdoor air and dust samples [12,14,19-23], in water [24,25], in soil and sediment [12-14,22,26,27] and in sewage sludge [13,22,26,28]. BFRs are detected in plants and 
wildlife throughout the food chain, in human tissues, blood serum and breast milk of exposed occupational populations (i.e. individuals working in the production of BFRs or production, recycling, or disposal of BFR-containing products) and in the general populations [12-14,20-22,25,26,29-42]. Furthermore, toxic (acute and chronic) and ecotoxic effects of some BFRs have been observed, including immunotoxicity, cytotoxicity, neurotoxicity, endocrine disruption, genotoxicity, mutagenicity, carcinogenicity and teratogenicity [4,6,8,26,27,43-47]. Despite these observations, only limited information is available on many BFRs, especially concerning the effect of BFRs on wildlife and man, their environmental fates and biodegradability potential.

Figure 1. Chemical structures of different flame retardants (FR). (A) inorganic FR: aluminium hydroxide; (B) organophosphorus FR: triphenylphosphate (C) nitrogencontaining FR: melamine; (D-F) halogenated organic FRs: (D) aliphatic FR: dibromoneopentyl glycol (DBNPG) (E) cycloaliphatic FR: hexabromocyclododecane (HBCD) and (F) aromatic FR: tetrabromobisphenol A (TBBPA).

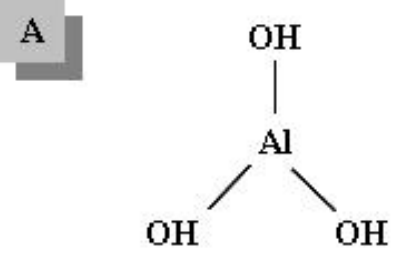

B

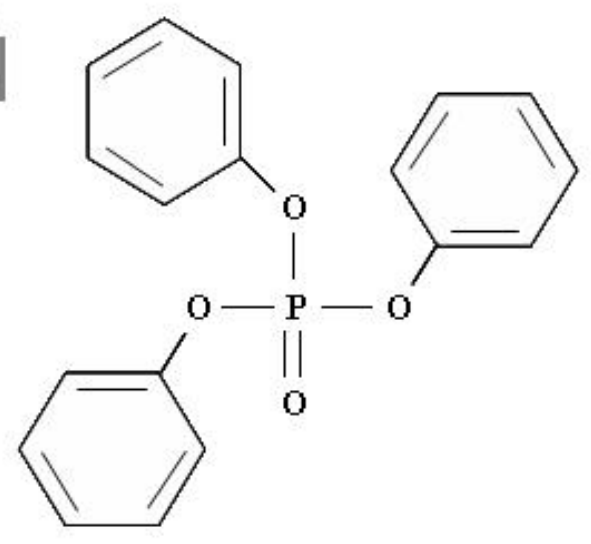

C

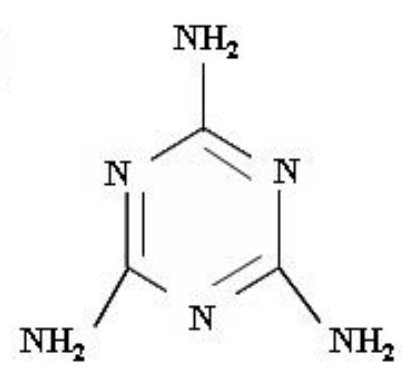

D<smiles>OCC(CO)(CBr)CBr</smiles>

E<smiles>BrC1CCC(Br)C(Br)CCC(Br)C(Br)CCC1Br</smiles>

F

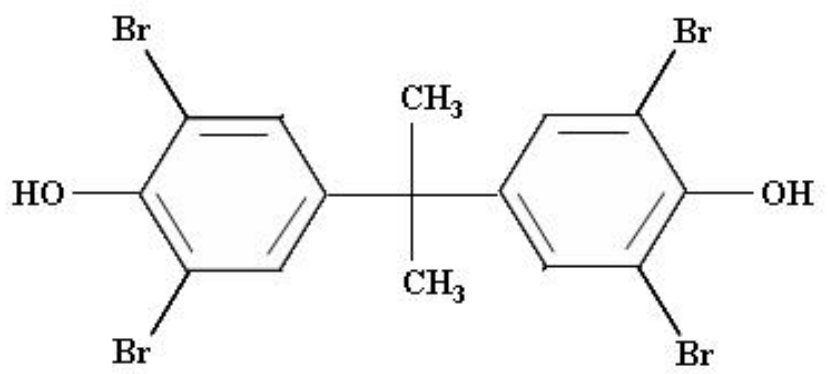




\section{Environmental Fate of Brominated Flame Retardants}

Like most of the halogenated organic compounds, BFRs generally have limited biodegradability, are persistent and tend to accumulate in the environment. However, in certain environmental conditions, a number of abiotic and biotic processes can occur. Abiotic processes are physicalchemical processes that include photodegradation, wet and dry deposition, decomposition at high temperature, chemical reactions with other compounds or radicals (e.g. hydroxyl, metals, etc.) that are present in the environment and changes in compound characteristics due to environmental factors, like temperature and $\mathrm{pH}$. Biotic processes can be defined as those biological processes that include bioaccumulation and entry into the food chain, biotransformation and biodegradation. All of these processes have the most significant environmental relevance when discussing the environmental fate of BFRs, as well as remediation of contaminated sites and risk assessment since such situations can change compound properties, including mobility, bioavailability and toxicity. Consequently, a compound can be modified to be less or even more toxic to plants, wildlife and man than was the original compound.

Photodegradation is a physical process known to occur naturally in the environment. Different PBDE congeners, like decabrominated diphenyl ether (BDE-209), can be photochemically degraded (via either UV or sunlight) in organic and aqueous solvent systems and in soils and sediments. Degradation results in the formation of less brominated PBDEs that can form more persistent and toxic lower brominated compounds [48,49]. Raff et al. estimated that $90 \%$ of lower brominated PBDEs, like $2,2^{\prime}, 4,4^{\prime}$-tetrabromodiphenyl ether (BDE-47), that enter the lower troposphere may be removed by photolysis before being deposited, with wet and dry deposition accounting for more then $95 \%$ of decabromodiphenyl ether (BDE-209) removal. Moreover, deposition processes control the loss of BDE-209 from the atmosphere and are responsible for the enhancement of BDE-209 found in sediment samples taken from lakes and rivers around the world [50]. TBBPA is also photolytically decomposed when exposed to UV light. The breakdown products correspond to different brominated organic compounds, like dibromophenol, 2,4,6-tribromophenol and di- and tribromobisphenol A [26].

There are studies that indicate that during thermal stress, PBDEs and TBBPA are converted to the dioxin-like compounds, polybrominated dibenzodioxins (PBDDs) and polybrominated dibenzofurans (PBDFs) [8].

Another process that may alter the bioavailability of compounds is changes in compound solubility due to environmental factors. For example, at neutral pH, TBBPA has very low solubility and its soil mobility is expected to be minimal. However, at higher $\mathrm{pH}$ (as in some arid soils areas), the solubility of TBBPA increases, making its soil mobility and potential for groundwater contamination considerable [51].

An important biotic process that affects the environmental ecotoxicity potential of a compound is its bioaccumulation. There is increasing evidence that some BFRs, like PBDE and HBCD, bioaccumulate in the food chain, as increasing concentrations of these BFRs are found in species higher in the food chain, such as zooplankton, invertebrates, fish and sea mammals [14,52-54]. Bioaccumulation of BFRs in the food chain is one of the ways that human can be exposed to BFRs, namely through diet, upon eating contaminated fish, meat, eggs, dairy products, etc [55]. 


\subsection{Biodegradation and Bioremediation}

Biodegradation process is one of the most significant processes experienced by organic compounds in the environment. The biodegradation process, which is (largely) mediated by microorganisms, can contribute to the reduction/complete elimination of organic contaminants in the environment [18]. Ideally, biodegradation of compounds in the environment would result in complete mineralization. However, this is not always the case, especially with complex compounds [56,57]. Aerobic and anaerobic biodegradation processes of halogenated organic compounds other than BFRs have been frequently reported [18,58-60]. Microorganisms can use halogenated organic compounds in four ways, namely as a carbon source and oxidizable substrate, as an electron acceptor in the 'halorespiration' process, in co-metabolic transformation, and in fermentative metabolism, in which a dehalogenated intermediate serves as an electron acceptor [61]. Halogen removal, i.e. the dehalogenation step, is the key reaction during the biodegradation of halogenated organic compounds. A number of dehalogenation enzymatic mechanisms are known to occur aerobically and anaerobically, mediated by a wide range of microorganisms [59-62]. Usually, halogen removal reduces compound resistance to biodegradation and the risk of forming toxic intermediates during subsequent metabolic steps [61]. However, this is not always the case, especially if the transformation does not result in complete mineralization of the compound such that brominated substituents remain.

Recently, several studies have been conducted addressing the biodegradation of different BFRs. Segev et al. have demonstrated the biodegradation of two aliphatic BFRs, dibromoneopentyl glycol (DBNPG) and tribromoneopentyl alcohol (TBNPA), under aerobic conditions by a bacterial consortium originating from soil sediments from a contaminated site. The biodegradation was accompanied by a release of bromide into the medium by a bacterial debromination reaction (Figure 2). Among the consortium members are known dehalogenating bacterial species [63,64]. 2,4,6tribromophenol (TBP) was found to be aerobically biodegraded during transport in low permeability fractured chalk cores. During transport, the physicochemical condition of the medium (e.g. an aquifer) must be considered, in addition to biological factors, such as residence time and physicochemical characteristics of the rock [65]. Brenner et al. tested various reactor systems added with contaminated sediments and cultivated with concentrated biomass acclimated to the treatment of industrial wastes for the biological treatment of a waste mixture containing bromo-organic compounds, including TBBPA and TBP. Although various redox conditions were applied and different carbon sources were tested, no TBBPA biodegradation was observed. TBP, on the other hand, was found to be easily biodegraded by aerobic cultures simulating the activated sludge process (Figure 3). This was linked to a consistent accumulation of bromides, released to the liquid following TBP breakdown [66]. TBP has also been found to undergo anaerobic biodegradation by different bacteria, such as Achromobacter piechaudii, Desulfovibrio stain TBP-1 and Ochrobacterium sp. strain TB01. The primary step in TBP biodegradation is an anaerobic reductive debromination reaction in which the halogenated organic compound is used as a final electron acceptor in a 'halorespiration' process [67-69]. Recent publications have demonstrated the anaerobic reductive debromination of different PBDEs, including decabromodiphenyl ether (BDE-209), by isolated bacteria, mixed cultures and fungi in mineral medium, as well as by sediment or sewage sludge [48,70-74]. The product generated from BDE-209 after debromination is more toxic and bioaccumulative than is the starting compound [72]. Davis et al. 
(2005) have shown HBCD biodegradation in aerobic and anaerobic soil and aquatic sediments. In this process, $\mathrm{HBCD}$ is sequentially debrominated by a dehalogenation mechanism known as dihaloelimination, where, at each step, there is a loss of two bromines from vicinal carbons with subsequent formation of a double bond between neighboring carbon atoms [75,76]. Ronen et al. described reductive debromination of TBBPA to bisphenol-A (BPA), a known estrogenic compound and suspected teratogen, under anaerobic conditions [77,78]. BPA can then undergo aerobic mineralization mediated by the Gram-negative aerobic bacterium strain WH1 of the genus Sphingomonas [57].

Figure 2. Debromination of dibromoneopentyl glycol (DBNPG) and tribromoneopentyl alcohol (TBNPA) by a bacterial consortium. (A) Bromide concentration in a DBNPG enrichment culture. (B) Bromide concentration in a TBNPA enrichment culture. The increase of bromide concentration in both culture is shown (black), as opposed to the value in control cultures (white) $[63,64]$.
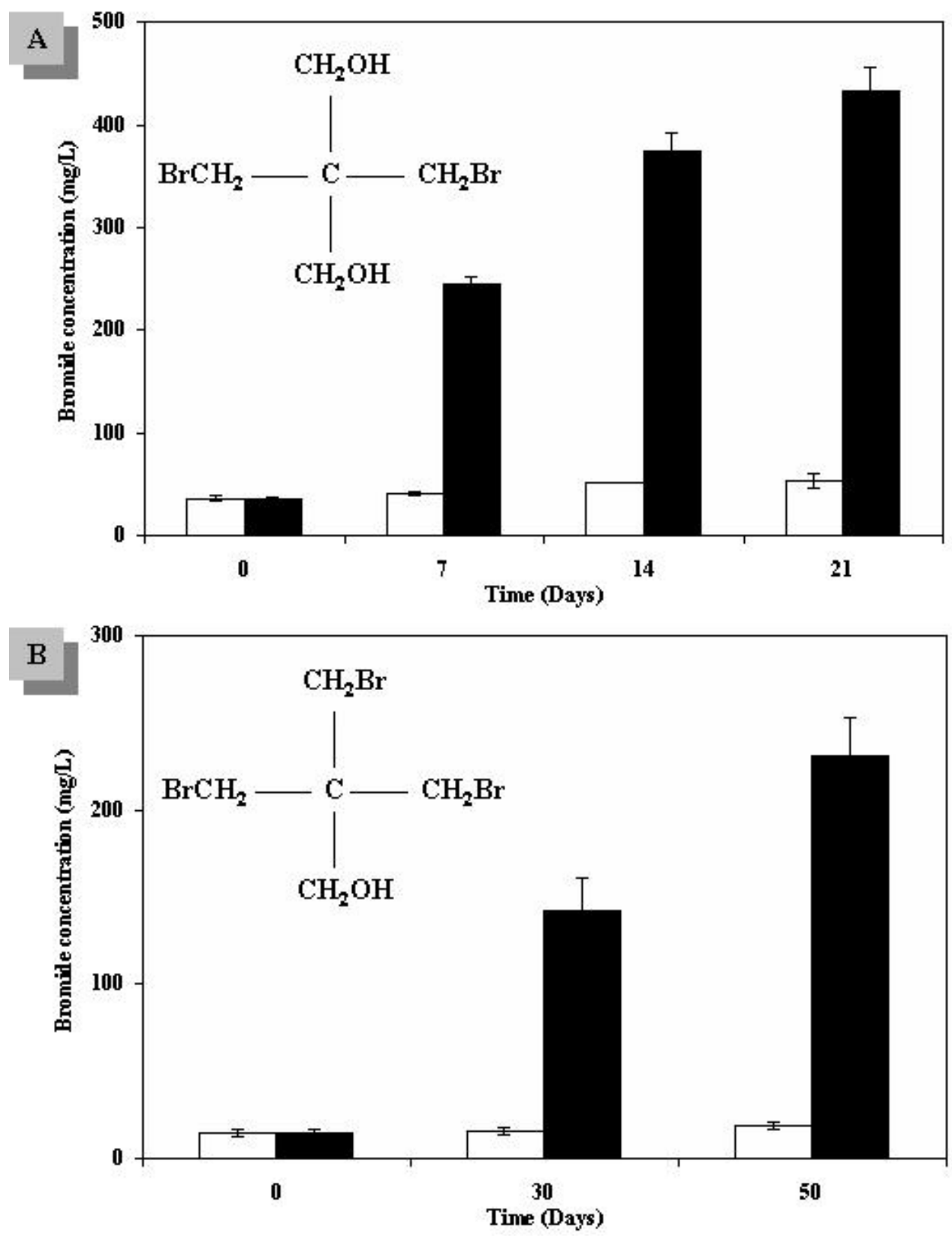
A compound can undergo other biotransformation reactions beside biodegradation in the environment. The origin of a dimethylated derivative of TBBPA that was found in sediments may be the methylation of TBBPA by microorganisms [26]. Indeed, Allard et al. have shown that Rhodococcus sp. strain 1395 is capable of O-methylating TBBPA under aerobic conditions. The reaction product is highly lipophilic, making the derivative more bioaccumulable than is TBBPA [79].

Remediation of contaminated sites by physical-chemical processes is expensive and labor-intensive and often results in shuffling toxicants from one place to another. A possible solution to this problem is intensive, targeted biological treatment based on the biodegradation of a compound by microorganisms. The fact that a compound in aqueous solution is utilized by microorganisms does not guarantee that the compound will be biodegradaed by the same microorganism in a complex environmental matrix, like soil, aquifer or sediment, all often associated with natural organic matter [18]. There are few studies regarding the bioremediation of halogenated organic compounds in contaminated sites [80]. It is thus essential to expand our knowledge and develop tools that will allow better understanding and mimicking of natural environmental conditions so as to enhance bioremediation of BFR-contaminated sites.

Figure 3. 2,4,6 Tribromophenol (TBP) aerobic biodegradation by aerobic cultures simulating activated sludge processes. TBP concentration $(\mathbf{A})$ in the reactor decreases while the bromide concentration ( $\boldsymbol{\square}$ ) increases. The accumulation of the bromide indicates a debromination reaction [66].

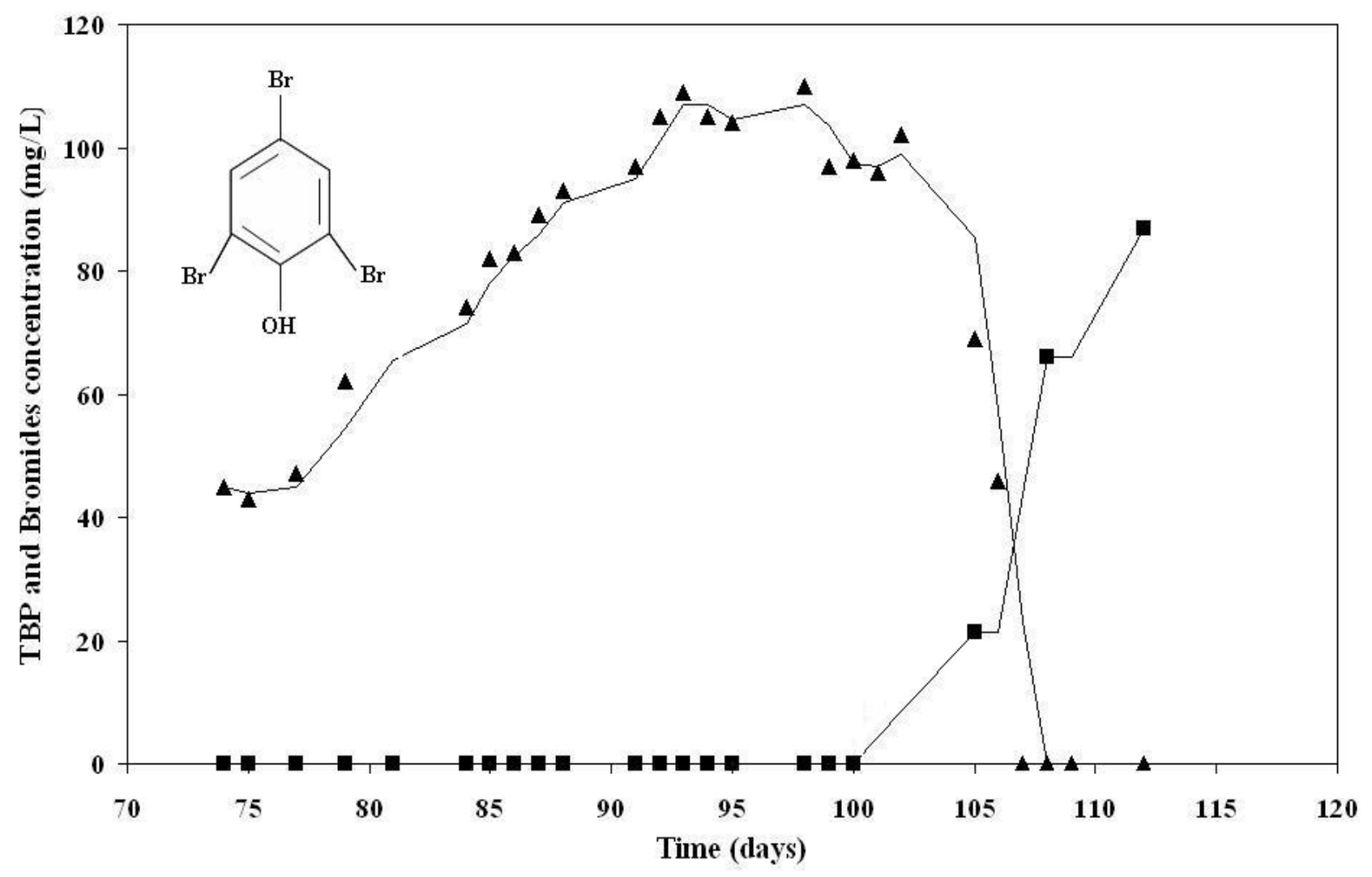




\section{Summary}

FRs constitute a large and diverse group of anthropogenic environmental contaminants used in numerous applications, including the manufacture of electronic equipment, textiles, plastic polymers and in the car industry, primarily to protect materials against ignition. Among the different FRs groups, the BFRs are the largest market group, because of their high performance efficiency and low cost. Recent reports have demonstrated the presence of BFRs at various concentrations in air, water, soil, wastewater and sediments far from the locations where they are produced. Moreover, traces of BFRs have been found in plants, wildlife and even in human samples. Thus, recent publications on the persistence, bioaccumulation and toxicity of some of BFRs are a source of great concern. Despite the information available on BFR distribution, many questions related to exposure, toxicology, metabolism and environmental occurrence and behavior remain unanswered. Remediation of contaminated sites by physical-chemical processes is expensive and labor-intensive and often results in shuffling toxicants from one place to another. A possible solution to this problem is thus controlled, targeted biological treatment. Taking into account the limited information available today, more research is needed regarding the fate and impact of FRs in the environment. Since certain abiotic and biotic processes can change compound characteristics and make them more persistent and toxic, it is important to investigate and understand the detailed biochemical transformation and degradation pathways, the microorganisms involved and the potential derivatives and intermediates generated.

\section{Acknowledgements}

This work was supported by the Israeli Ministry of Science and Technology and by the German BMBF (Cooperation in Water Technologies, Grant WT-501), and by the Ramat-Hovav Industrial Council, Israel. O.S. funding by the Rieger Foundation and the Israel Commercial Industrial Club is also gratefully acknowledged.

\section{References}

1. Alaee, M.; Wenning, R.J. The significance of brominated flame retardants in the environment: current understanding. Issues and challenges. Chemosphere 2002, 46, 579-582.

2. Market Study Flame Retardants. Ceresana Research: Konstanz Germany, 2008. www.ceresana.com/en/market-studies/additives/flame-retardants (accessed February 4, 2009).

3. Levchik, S.V. Introduction to flame retardancy and polymer flammability. In Flame retardant polymer nanocomposites; Morgan, A.B., Wilkie, C.A., Eds.; John Wiley \& Sons: NY, USA, 2007; pp. 1-29.

4. Birnbaum, L.S.; Staskal, D.F. Brominated flame retardants: cause for concern? Environ. Health Perspect. 2004, 112, 9-17.

5. Murphy, J. Modifying specific properties: flammability-flame retardants. In Additives for plastics handbooks; Elsevier Science Ltd.: New York, NY, USA, 2001; pp. 115-140. 
6. Alaee, M.; Arias, P.; Sjödin, A.; Bergman, Å. An overview of commercially used brominated flame retardants, their applications, their use patterns in different countries/regions and possible modes of release. Environ. Int. 2003, 29, 683-689.

7. Hartmann, P.C.; Burgi, D.; Giger, W. Organophosphate flame retardants and plasticizers in indoor air. Chemosphere 2004, 57, 781-787.

8. Janssen, S. Brominated flame retardants rising levels of concern. Health Care With Out Harm (HCWH): Arlington, VA, USA, 2005.

9. Carlsson, H.; Nilsson, U.; Stman, C. Video display units: an emmition source of the contact allergenic flame retardant triphenyl phosphate in the indoor environment. Environ. Sci. Technol. 2000, 34, 3885-3889.

10. Andresen, J.A.; Grundmann, A.; Bester, K. Organophosphorus flame retardants and plasticisers in surface waters. Sci. Total Environ. 2004, 332, 55-166.

11. Marklund, A.; Andersson, B.; Haglund, P. Screening of organophosphorus compounds and their distribution in various indoor environments. Chemosphere 2003, 53, 1137-1146.

12. De Wit, C.A.; Alaee, M.; Muir, D.C.G. Levels and trends of brominated flame retardants in the Arctic. Chemosphere 2006, 64, 209-233.

13. Law, R.J.; Allchin, C.R.; De Boer, J.; Covaci, A.; Herzke, D.; Lepom, P.; Morris, S.; Tronczynski, J.; De Wit, C.A. Levels and trends of brominated flame retardants in the European environment. Chemosphere 2006, 64, 187-208.

14. Law, R.J.; Herzke, D.; Harrad, S.; Morris, S.; Bersuder, P.; Allchin, C.R. Levels and trends of HBCD and BDEs in the European and Asian environments with some information for other BFRs. Chemosphere 2008, 73, 223-241.

15. Quintana, J.B.; Rodil, R.; Reemtsma, T.; Garcia-Lopez, M.; Rodrigues, I. Organophosphorus flame retardants and plasticizers in water and air II. Analytical methology. Trends Analyt. Chem. 2008, 27, 904-915.

16. Tohka, A.; Zevenhoven, R. Brominated flame retardants - a nuisance in thermal waste processing. Presented at TMS Fall 2002 Extraction and Processing Division Meeting on Recycling and Waste treatment in Mineral and Metal Processing. Technical and Economics Aspects, Lulea, Sweden, June 16-20, 2002.

17. Troitzsch, J.H. Overview of flame retardant. Chemistry Today 1998, 16, January/February

18. Häggblom M.M.; Bossert I.D.: Dehalogenation - Microbial processes and environmental applications; Kluwer Academic Publishers: Norwell, MA, USA, 2003.

19. Sjödin, A.; Carlsson, H.; Thuresson, K.; Sjölin, S.; Bergman, Å.; Östman, C. Flame retardants in indoor air at an electronics recycling plant and at other work environment. Environ. Sci. Technol. 2001, 35, 448-454.

20. Sjödin, A.; Patterson Jr., D.G.; Bergman, A. A review on human exposure to brominated flame retardants - particularly polybrominated diphenyl ethers. Environ. Int. 2003, 29, 829-839.

21. Stapleton, H.M.; Dodder, N.G.; Offenberg, J.H.; Schntz, M.M.; Wise, S.A. Polybrominated diphenyl ethers in house dust and clothes dryer lint. Environ. Sci. Technol. 2005, 39, 925-931.

22. Hale, R.C.; La Guardia, M.J.; Harvey, E.; Gaylor, M.O.; Mainor, T.M. Brominated flame retardant concentration and trends in abiotic media. Chemosphere 2006, 64, 181-186. 
23. Tollbäck, J.; Crescenzi, C.; Dyremar, E. Determination of the flame retardant tetrabromobisphenol A in air samples by liquid chromatography-mass spectrometry. $J$. Chromatogr A 2006, 1104, 106-112.

24. Watanabe, I.; Sakai, S.I. Environmental release and behavior of brominated flame retardants. Environ. Int. 2003, 29, 665-682.

25. Remberger, M.; Sternbeck, J.; Palm, A.; Kaj, L.; Strömberg, K.; Brorström-Luden, E. The environmental occurrence of hexabromocyclododecane in Sweden. Chemosphere 2004, 54, 9-21.

26. De Wit, C.A. An overview of brominated flame retardants in the environment. Chemosphere 2002, 46, 583-624.

27. De Boer, J.; Wester, P.G.; Van der Horst, A.; Leonards, P.E.G. Polybrominated diphenyl ethers in influents, suspended particulate matter, sediments, sewage treatment plant and effluents and biota from Netherlands. Environ. Pollut. 2003, 122, 63-74.

28. Kupper, T.; De Alencastro, L.F.; Gatsigazi, R.; Furrer, R.; Grandjean, D.; Tarradellas, J. Concentrations and specific loads of brominated flame retardants in sewage sludge. Chemosphere 2008, 71, 1173-1180.

29. Sjödin, A.; Hagmar, L.; Klasson-Wehler, E.; Kronholm-Diab, K,; Jakobsson, E.; Bergman, A. Flame retardant exposure: Polybrominated diphenyl ethers in blood from Swedish workers. Environ. Health Perspect. 1999, 107, 643-648.

30. Blanck, H.M.; Marcus, M.; Hertzberg, V.; Tolbert, P.E.; Rubin, C.; Henderson, A.K. Determinants of polybrominated biphenyl serum decay among women in the Michigan PBB cohort. Environ. Health Perspect. 2000, 108, 147-152.

31. Jakobsson, K.; Thuresson, K.; Rylander, L.; Sjodin, A.; Hagmar, L.; Bergman, A. Exposure to polybrominated diphenyl ethers and tetrabromobisphenol A among computer technicians. Chemosphere. 2002, 46, 709-716.

32. Lind, Y.; Darnerud, P.O.; Atuma, S.; Aune, M.; Becker, W.; Bjerseliius, R.; Canattingius, S.; Glynn, A. Polybrominated diphenyl ethers in breast milk from Uppsala County, Sweden. Environ. Res. 2003, 93, 186-194.

33. Weiss, J.; Meijer, L.; Sauer, P.; Linderholm, L.; Bergman, A.; Athanassiadis, I. PBDE and HBCD levels in blood from Dutch mothers and infants - analysis of a Dutch Groningen infant cohort. Organohalogen Compound. 2004, 66, 2677-2682.

34. Herzke, D.; Berger, U.; Kallenborn, R.; Nygard, T.; Vetter, W. Brominated flame retardants and other organobromines in Norwegian bird eggs. Chemosphere 2005, 61, 441-449.

35. Janak, K.; Covaci, A.; Voorspoels, S.; Becher, G. Hexabromocyclododecane in marine species from the Western Scheldt Estuary: diastereoisomer- and enantiomer- specific accumulation. Environ. Sci. Technol. 2005, 39, 1987-1994.

36. Muir, D.C.G.; Backus, S.; Derocher, A.E.; Dietz, R.; Evans, T.J.; Gabrielsen, G.W.; Nagy, J.; Norstrom, R.J.; Sonne, C.; Stirling, I.; Taylor, M.K.; Letcher, R.J. Brominated flame retardant in Polar bear (Ursus maritimus) from Alaska, the Canadian Arctic, East Greenland and Svalbard. Environ. Sci. Technol. 2006, 40, 449-455.

37. Jenssen, B.M.; Sǿrmo, E.G.; Baek, K.; Bytingsvik, J.; Gaustad, H.; Ruus, A.; Skaare, J.U. Brominated flame retardants in North-East Atlantic Marine Ecosystems. Environ. Health Perspect. 2007, 115, 35-41. 
38. Thomsen, K.; Molander, P.; Daae, H.L.; Janak, K.; Froshaug, M.; Liane, V.H.; Thorud, S.; Becher, G.; Dybing, E. Occupational exposure to Hexabromocyclododecane at an Industrial Plant. Environ. Sci. Technol. 2007, 41, 5210-5216.

39. Johnson-Restrepo, B.; Adams, D.H.; Kannan, K. Tetrabromobisphenol A (TBBPA) and hexabromocyclododecanes (HBCDs) in tissues of humans, dolphins, and sharks from the United States. Chemosphere 2008, 70, 1935-1944.

40. Kakimoto, K.; Akutsuk, K.; Konishi, Y.; Tanaka, Y. Time trend of hexabromocyclododecane in the breast milk of Japanese women. Chemosphere 2008, 71, 1110-1114.

41. Polder, A.; Venter, B.; Skaare, J.U.; Bouwman, H. Polybrominated diphenyl ethers and HBCD in bird eggs of South Africa. Chemosphere 2008, 73, 148-154.

42. Roosens, L.; Dirtu, A.C.; Goemans, G.; Belpaire, C.; Gheorghe, A.; Neels, H.; Blust, R.; Covaci, A. Brominated flame retardants and polychlorinated biphenyls in fish from the river Scheldt, Belgium. Environ. Int. 2008, 34, 976-983.

43. Simonsen, F.A.; Stavnsbjerg, M.; Møller, L.M.; Madsen, T. Brominated flame retardants: Toxicity and ecotoxicity; Environment project No.568. Danish Environmental Protection Agency: København, K Denmark, 2000.

44. Darnerud, P.O. Toxic effects of brominated flame retardants in man and in wildlife. Environ. Int. 2003, 29, 841-853.

45. Mariussen, E.; Fonnum, F. The effect of brominated flame retardants on neurotransmitter uptake into rat brain synaptosomes and vesicles. Neurochem. Int. 2003, 43, 533-542.

46. Canesi, L.; Lorusso, L.C.; Ciacci, C.; Betti, M.; Gallo, G. Effects of the brominated flame retardant tetrabromobisphenol-A (TBBPA) on cell signaling and function of Mytilus hemocytes: involvement of MAP kinases and protein kinase C. Aquat. Toxicol. 2005, 75, 277-287.

47. Legler, J. New insight into the endocrine disrupting effects of brominated flame retardants. Chemosphere 2008, 73, 216-222.

48. Rayne, S.; Ikonomou, M.G.; MacMurray, D.W. Anaerobic microbial and photochemical degradation of 4,4'-dibromodiphenyl ether. Water Res. 2003, 37, 551-560.

49. Eriksson, J.; Green, N.; Marsh, G.; Bergman, A. Photochemical decomposition of 15 polybrominated diphenyl ether congeners in methanol/water. Environ. Sci. Technol. 2004, 38, 3119-3125.

50. Raff, J.; Hites, R. Deposition versus photochemical removal of PBDEs from Lake Superior air. Environ. Sci. Technol. 2007, 41, 6725-6731.

51. Hakk, H.; Letcher, R.J. Metabolism in the toxicokinetics and fate of brominated flame retardants - a review. Environ. Int. 2003, 29, 801-828.

52. Boon, J.P.; Lewis, W.E.; Tjoen-A-Choy, M.R.; Allchin, C.R.; Law, R.J.; De Boer, J.; HallersTjabbes, C.C.T.; Zegers, B.N. Levels of Polybrominated diphenyl ether (PBDE) flame retardants in animals representing different trophic levels of the North Sea food web. Environ. Sci. Technol. 2002, 36, 4025-4032.

53. Bayen, S.; Wurl, O.; Karuppiah, S.; Sivasothi, N.; Lee, H.K.; Obbard, J.P. Persistent organic pollutants in mangrove food webs in Singapore. Chemosphere 2005, 61, 303-313.

54. Sǿrmo, E.G.; Salmer, M.P.; Jenssen, B.M.; Hop, H.; Baek, K.; Kovacs, K.M.; Lydersen, C.; FalkPetersen, S.; Gabrielsen, G.W.; Lie, E.; Skaare, J.U. Biomagnification of polybrominated 
diphenyl ether and hexabromocyclododecane flame retardants in the polar bear food chain in Svalbard, Norway. Environ. Toxicol. Chem. 2006, 25, 2502-2511.

55. Schecter, A.; Päpke, O.; Tung, K.C.; Staskal, D.; Birnbaum, L. Polybrominated diphenyl ethers contamination of United States food. Environ. Sci. Technol. 2004, 38, 5306-5311.

56. Camara, B.; Herrera, C.; Gonzalez, M.; Couve, E.; Hofer, B.; Seeger, M. From PCBs to highly toxic metabolites by the biphenyl pathway. Environ. Microbiol. 2004, 6, 842-850.

57. Ronen, Z.; Abeliovich, A. Anaerobic-aerobic process for microbial degradation of Tetrabromobisphenol A. Appl. Environ. Microbiol. 2000, 66, 2372-2377.

58. Chaudhry, G.R.; Chapalamadugu, S. Biodegradation of Halogenated Organic Compounds. Microbiol. Rev. 1991, 55, 59-79.

59. Fetzner, S.; Lingens, F. Bacterial dehalogenases: biochemistry, genetics, and biotechnological applications. Microbiol. Mol. Biol. Rev. 1994, 58, 641-685.

60. Smidt, H.; De Vos, W.M. Anaerobic microbial dehalogenation. Annu. Rev. Microbiol. 2004, 58, 43-73.

61. Janssen, B.D.; Oppentocht, J.E.; Poelarends, G.J. Microbial dehalogenation. Curr. Opin. Biotechnol. 2001, 12, 254-258.

62. Van Pee, K.H.; Unversucht, S. Biological dehalogenation and halogenation reactions. Chemosphere 2003, 52, 299-312.

63. Segev, O.; Abeliovich, A.; Kushmaro, A. Biodegradation of Dibromoneopentyl glycol by bacterial consortium. Chemosphere 2007, 68, 958-964.

64. Segev, O.; Meusel, W.; Friedenberger, M.; Brenner, A.; Kushmaro, A. Aerobic biodegradation of the brominated flame retardants, Dibromoneopentyl Glycol and Tribromoneopentyl Alcohol. Biodegradation 2009 (in press).

65. Arnon, S.; Eilon, A.; Ronen, Z.; Nejidat, A.; Yakirevich, A.; Nativ, R. Biodegradation of 2,4,6Tribromophenol during transport in fractured chalk. Environ. Sci. Technol. 2005, 39, 748-755.

66. Brenner, A.; Mukmanov, I.; Abeliovich, A.; Kushmaro, A.: Biodegradability of tetrabromobisphenol A and tribromophenol by activated sludge. Ecotoxicology 2006, 15, 399402.

67. Boyle, A.W.; Phelps, C.D.; Young, L.Y. Isolation from Estuarine Sediments of a Desulfovibrio strain which can grow on lactate coupled to the reductive dehalogenation of 2,4,6-tribromophenol. Appl. Environ. Microbiol. 1999, 65, 1133-1140.

68. Ronen, Z.; Vasiluk, L.; Abeliovich, A.; Nejidat, A. Activity and survival of tribromophenol degrading bacteria in a contaminated desert soil. Soil Biol. Biochem. 2000, 32, 1643-1650.

69. Takashi, Y.; Takahama, Y.; Yamada, Y. Biodegradation of 2,4,6-tribromophenol by Ochrobacterium sp. Strain TB01. Biosci. Biotechnol. Biochem. 2008, 72, 1264-1271.

70. Gerecke, A.C.; Giger, W.; Hartmann, P.C.; Heeb, N.V.; Kohler, H.P.E.; Schmid, P.; Zennegg, M.; Kohler, M. Anaerobic degradation of brominated flame retardants in sewage sludge. Chemosphere. 2006, 64, 311-317.

71. He, J.; Robrock, K.R.; Alvarez-Cohen, L. Microbial Reductive Debromination of Polybrominated Diphenyl Ethers (PBDEs). Environ. Sci. Technol. 2006, 40, 4429-4434. 
72. Zhou, J.; Jiang, W.; Ding, J.; Zhang, X.; Gao, S. Effect of Tween 80 and $\beta$-cyclodextrin on degradation of decabromodiphenyl ether (BDE-209) by White Rot Fungi. Chemosphere. 2007, 70, 172-177.

73. Robrock, K.R.; Korytar, P.; Alvarez-Cohen, L. Pathways for the anaerobic microbial debromination of polybrominated diphenyl ethers. Environ. Sci. Technol. 2008, 42, 2845-2852.

74. Tokarz, J.A III.; Ahn, M.Y.; Leng, J.; Filley, T.R.; Nies, L. Reductive debromination of polybrominated diphenyl ethers in anaerobic sediment and a biomimetic system. Environ. Sci. Technol. 2008, 42, 1157-1164.

75. Davis, J.W.; Gonsior, S.; Marty, G.; Ariano, J. The transformation of hexabromocyclododecane in aerobic and anaerobic soils and aquatic sediments. Water Res. 2005, 39, 1075-1084.

76. Davis, J.W.; Gonsior, S.; Markham, D.A.; Friederich, U.; Hunziker, R.W.; Arianob, J. Biodegradation and product identification of $\left[{ }^{14} \mathrm{C}\right]$ hexabromocyclododecane in wastewater sludge and freshwater aquatic sediments. Environ. Sci. Technol. 2006, 40, 5395-5401.

77. Steinmetz, R.; Mitchner, N.A.; Grant, A.; Allen, D.L.; Bigsby R.M.; Ben-Jonathan N. The xenoestrogen bisphenol A induces growth, differentiation, and c-fos gene expression in the female reproductive tract. Endocrinology 1998, 139, 2741-2747.

78. Welshons, W.V.; Nagel, S.C.; Vom Saal, F.S. Large effects from small exposures. III. Endocrine mechanisms mediating effects of bisphenol A at levels of human exposure. Endocrinology 2006, 147, S56-S69.

79. Allard, A.S.; Remberger, M.; Neilson, A.H. Bacterial O-Methylation of halogen-substituted phenols. Appl. Environ. Microbiol. 1987, 53, 839-845.

80. Häggblom, M.M.; Fennel, D.E.; Ahn, Y.B.; Ravit, B.; Kerkhof, L.J. Anaerobic dehalogenation of halogenated organic compound: Novel strategies for bioremediation of contaminated sediments. In Soil and Water Pollution Monitoring, Protection and Remediation. Twardowska, I.; Allen, H.E.; Häggblom, M.; Stefaniak, S. Eds.. Springer: Dordrecht, The Netherlands, 2006; pp. 505521.

(C) 2009 by the authors; licensee Molecular Diversity Preservation International, Basel, Switzerland. This article is an open-access article distributed under the terms and conditions of the Creative Commons Attribution license (http://creativecommons.org/licenses/by/3.0/). 